\title{
Investigation on the Screening Model of Chemical Hazards Based on the Risk of Domino Effect and Terrorist Attack
}

\author{
Huang Wenduo ${ }^{1}$, Shao Xuechun ${ }^{1}$, Wang Jiajie ${ }^{1},{\text { Xiao } \text { Yang }^{1} \text {,Sun Dongliang }}^{1}$ \\ ${ }^{1}$ State Environmental Protection Key Laboratory of Environmental Risk Assessment and Control on Chemical Process, School of \\ Resources and Environmental Engineering, East China University of Science and Technology, Shanghai 200237, China
}

\begin{abstract}
The heavy losses are often caused in modern chemical plants at the time of the accident. In order to prevent accidents, the screening and identification of hazards is needed. In this paper, the screening model of hazards in chemical plants was studied under the domino effect and the risk of terrorist attack. According to the threshold and strength of the domino effect of the unit under the main accident scenarios, the index of domino effect was developed. The risk index of terrorist attacks was determined in line with the distance between the unit and the boundary under the assumption of terrorist attacks. The hazards screening model $Z$ was designed based on two aspects of the study. The model was applied in screening the hazards. The results showed that closer units near the border were more dangerous under the risk of terrorist attack, and the devices surrounded by units with greater influence of accidents were more dangerous under the risk of domino effect. The indices of the tanks were ordered: $Z_{105}>Z_{101}>Z_{103}>Z_{106}>Z_{104}>Z_{102}>Z_{201}>Z_{202}>Z_{203}>Z_{204}>Z_{205}>Z_{206}>Z_{303}>Z_{304}>Z_{301}>Z_{302}>Z_{306}>Z_{305}$. The domino effect and the risk of terrorist attacks were combined into the present model for perfection and correction of the existing hazards screening model, as the new basis for major hazards identification.
\end{abstract}

\section{Introduction}

The modern chemical industry is developing in the direction of the large-scale equipment. Not only the equipment and technology are intensive, but also the units are closely linked. Furthermore, there are a large number of inflammable and explosive materials (such as fuel oil, olefins, aromatics). The leakage of the above material encountering incendiary source will result in fire and explosion which caused casualties, property loss and environmental pollution, more far-reaching social impact, so the chemical industry has high risk characteristics. In chemical accidents, the domino effect is a typical phenomenon of escalation of accident severity, with a higher frequency. The related research defined it as "the damage effect produced by the chemical unit accident (initial accident) under certain conditions to the surrounding other units caused two or more accidents, and the promotion of the accident effect was expanded" ${ }^{[1]}$. At the same time, not only the important target of the chemical industry (such as the strategic reserve base of crude oil and the oil depot) is the lifeblood of chemical production, but also it easily turns to the target of terrorist attack. Terrorist attacks are man's subjective intentional behavior ${ }^{[2]}$. Although risk analysis was based on system failure and human error in the field of traditional safety science, the deliberate destruction of human beings has never been taken into account. In particular, only the inherent characteristics of hazard sources and risk of domino effect has been considered, the risk of terrorist attack has not been identified as an identification factor in the chemical industry.

Therefore, a screening model of hazard sources for chemical industrial areas based on domino effect and terrorist attack risk was established in paper. The domino effect index and the terrorist attack risk index were comprehensively considered on the basis of the fire and explosion index of the chemical unit. A comprehensive index model for hazard screening was built which was used as the identification index of hazard sources in chemical industry area. All the units in the area were sorted by synthetically index to determine the units with higher risk in order to carry out safety supervision and risk protection in a targeted manner, and reduce the risk of regional accident loss as well.

\section{Methods for Establishing Screening Model of Chemical Hazards Based on Risk of Domino Effect and Terrorist Attack}

\subsection{Index of Fire and Explosion}

The number of hazardous substances in the chemical unit was used as the basis for evaluating the hazard size of the chemical unit, moreover, the property and state indices were used as a correction. The calculation was intended to quantitatively assess the risk of the matter on the basis of the dangerous nature and state of the material. This can be achieved in the form of three exponential multiplies. 
Through the analysis above, the three indices were synthesized as fire and explosion index:

$$
W=W_{1} \cdot W_{2} \cdot W_{3}
$$

where: $\mathrm{W}$ - the index of fire and explosion in chemical unit; $\mathrm{W}_{1}$ - the index of the number of dangerous materials; $\mathrm{W}_{2}$ - the index of the nature of hazardous materials; $\mathrm{W}_{3}$ — the index of dangerous material states.

\subsection{Index of Domino effect}

According to thresholds of domino effect, the main accident scenarios corresponding to the surrounding chemical units and the domino effect vectors. In the light of the ratio of domino effect strength $E$ generated by the main accident scene around the chemical unit and domino failure threshold R, the index of domino effect hazard index D was obtained:

$$
D=E / R
$$

where: D-the hazard index of domino effect; E-domino upgrade vector strength; $\mathrm{R}$ - domino failure threshold.

The hazard index of domino effect was used as the correction index of the chemical unit's own risk, and the results of the two multiplied were treated as the hazard index of the chemical unit under the domino effect. Without considering the risk of terrorist attacks, the calculation method could be regarded as the basis for screening risk sources of chemical units under the risk of domino effect.

The main consideration of this method was that: As the chemical unit would have active or passive protection measures, such as automatic sprinkler, foam extinguishing, etc., which would play a protective role in the accident state. There may be between the units such as firewalls, fire dikes which have a blocking effect on accidents. In some special cases, such as projectile debris, the damage could only be caused by the existence of equipment at a certain distance in the direction of flight. All these reasons lead to uncertainty in the domino accident. Therefore, the risk index confirmed by this method was only the risk size of the domino scenarios in the unit.

\subsection{Index of Terrorist Attacks Risk}

We need to make the following assumptions when analyzing the risk of terrorist attacks:

(1) The security work could be regarded as reliable;

(2) The choice of the target of chemical industry area was completely random;

(3) Terrorist attacks were individual activities.

The reasons for hypothesis (1) were as mentioned above.

The reason for assumption (2) was to exclude the impact of chemical unit value on the attractiveness of a terrorist attack. That is, terrorists randomly chose chemical units. It was difficult to distinguish from the appearance in the ordinary people, because the chemical equipment was often like tower, tank shaped, and so on. Moreover, the role of chemical units was not the same as production, so the choice of attack target was unable to determine the value, consequences and so on. In this case, the impact of characteristics of chemical unit could be elided on the risk of terrorist attacks.

Assumption (3) was based on the characteristics of terrorist activities. Here referred to the behavior of the individual attacks launched by individual terrorists. Terrorist attacks are generally started by terrorist organizations and few individuals have launched attacks on chemical areas due to dissatisfaction with the society and other factors. It can be deemed to a single terrorist when considering the risk of a terrorist attack. In the case of collective action, it was likely that a large number of terrorists have crossed into the boundary of the chemical area and already entered the chemical area. Under such circumstances, terrorists entering the chemical industry may chose to attack some important nodes, such as the control room of a chemical plant, which may cause casualties as well as uncontrollable loss of chemical plant equipment. However, the risk of terrorist attacks has exceeded the scope of chemical safety research in this case and has already belonged to the subject of political and social studies.

Under the above three assumptions, the scope of the general terrorist attack can be made sure. It was most likely that the bombing were triggered by ammonium nitrate explosive in the region for chemical terrorist attacks. The terrorist attacks used explosives whose number of general will not exceed $50 \mathrm{~kg}$ when only be carried by a single person. Vehicles and other dangerous goods need to be reported to the public security department for approval. On the contrary, it was have great potential to succeed that the use of ammonium nitrate explosive initiated terrorist attacks can escape the general traffic and public security check.

TNT equivalent nitramon was approximately $1.5: 1$, which $1.5 \mathrm{~kg}$ ammonium nitrate explosive was roughly equivalent to $1 \mathrm{~kg}$ TNT. So the TNT equivalent of $50 \mathrm{~kg}$ ammonium nitrate explosive was approximately $33 \mathrm{~kg}$. The influence of the explosion of homemade explosives on chemical units can be calculated at different distances. The total energy of explosion was camputed:

$\mathrm{E}=268.488 \mathrm{MJ}$

$\mathrm{R}^{\prime}=\ln \mathrm{r} / 2.145=\ln \mathrm{r}-\ln 2.145=\ln \mathrm{r}-0.763$

The distance between the overpressure and the center of explosion was obtained based on the total energy of explosion and the dimensionless distance:

$\ln P_{S}-11.526=0.926-1.5058 \ln r+1.148+0.167 \ln 2 r-0.2548 \ln$

$r+0.582-0.032 \ln 3 r+0.014-0.0558 \ln r+0.0732 \ln 2 r$

After sorting out the relationship:

$\ln P_{\mathrm{S}}=14.196-1.8164 \ln r+0.2402 \ln ^{2} r-0.032 \ln ^{3} r$

Formula (3) was the relationship between the unit overpressure and the explosion center in the terrorist attack scenario.

The overpressure of the unit at a certain distance from the boundary of the chemical zone can be calculated according to the distance between overpressure and the center of explosion. In the light of the ratio of the overpressure value to the threshold of the device, the risk index of the terrorist attack failure can be computed:

$$
T=P_{\mathrm{S}} / R_{\mathrm{P}}
$$

where: $\mathrm{T}-$ Chemical unit terrorist attack risk index; RP-Unit overpressure threshold. 
The calculated overpressure was smaller than the failure threshold of the unit. The calculated the risk index computed of terrorist attack was less than 1 why the distance between the chemical plant and the chemical industry boundary was far away. But in fact, the risk index unit will not be reduced, thus the risk index of terrorist attacks should be counted at 1 when the calculated explosion overpressure was less than the failure threshold of the device in the practical application.

It was necessary to point out that the explosive effects of military explosives and industrial explosives were mostly caused by shock waves produced by explosions. In explosive explosion at high detonation speed which would produce very little light and short duration. Most of the explosion energy was converted into shock wave energy. It was essential to consider the impact of shock wave on the equipment while the effect of heat can be ignored when evaluating the impact of terrorist attacks on chemical equipment.

The obtained terrorist attack risk index was used as a risk correction index for chemical units under terrorist attack risk. The product of the risk index of fire and explosion and terrorist attack risk index of chemical unit was the danger index of chemical unit under the risk of terrorist attack. Combined with the domino effect risk index, the risk index of the chemical unit under the domino effect and terrorist attack risk was gained.

\subsection{Designed Screening Model of Chemical Hazards}

Based on the above analysis, the risk index of chemical unit under the domino effect and terrorist attack risk was showed:

$$
Z=W \cdot D \cdot T
$$

where: $Z$ - The risk index of chemical unit under the domino effect and terrorist attack risk.

The selected units in the chemical industry area were ranked according to the obtained hazard index. The risk size of the chemical unit can be acquired on the basis of the risk index of the chemical unit why the risk index represented the risk of the chemical unit under the domino effect and terrorist attack risk. The more dangerous chemical unit had greater risk index, so the chemical unit with larger risk index could be selected for targeted safety analysis and improvement.

What need to be pointed out was that the screening model only thought over the theoretical domino effect and the danger of terrorist attacks in the chemical unit, so it was relatively rough to the evaluation of the chemical unit. Due to the complexity of the domino effect, the international and domestic research on the domino effect was also in its infancy, and the understanding of domino accident was not comprehensive. Only the risk of the typical accident scene of the chemical unit in the surrounding equipment was analyzed in this study. The actual risk was greater because chemical equipment may have different types of accidents under different circumstances.

Only the risk of chemical units was considered and the safety measures were not taken into account. In the actual situation, the risk of chemical units would be greatly reduced due to the use of fire protection and safety measures in chemical equipment. However, the adoption of safety measures could not completely eliminate the essential risk of the unit. The influence of intrinsic safety measures on its intrinsic risk in the model of hazard screening was taken into account the risk assessment of chemical unit in this study. Therefore, the method presented in this paper was quite comprehensive for assessing the risk of chemical units in the case of essential safety.

It was mainly to assess the impact of accidents caused by dangerous sources for the evaluation of dangerous sources. The first was the possibility of accident; the second was the seriousness of the accident and the third was the ability to control the accident ${ }^{[3]}$. Taking into account the three factors, the risk of chemical unit could be estimated. In the model studied in this paper, the consideration of factors such as the number of substances could be used to assess the severity of the accident. The possibility of accidents could be appraised by considering the factors such as the state of matter, the nature and the distance between the element and the boundary. The consideration of main accidents and other factors in the domino accident scene was the evaluation of the impact of domino accident. Therefore, this model was more comprehensive for the assessment of risk sources in terms of the hazard of chemical units.

After the establishment of the screening model of major hazard sources, the potential risks could be investigated and eliminated according to the risk index. It was necessary for reducing regional risk and eliminating timely of hidden dangers that setting up a major accident prevention mechanism, to standardize and implement the general investigation of major accidents, establishing a database of major hidden trouble, and achieving dynamic tracking of the rectification of potential accidents on the basis of major hazard identification, evaluation ${ }^{[4]}$.

\section{Case Study and Results Analysis}

Storage tank was a kind of important equipment in the area of chemical equipment. Storage tanks included tanks for chemical products, storage tanks for raw materials, and material buffer tanks for production. The storage tank was a major hazard source because its storage capacity was usually large and its storage time was long. At the same time, it would be affected by the open environment. A typical tank in the chemical industry area was selected to analyze and verify the rationality of the calculation process of the screening model of the hazard sources.

The selected chemical tank area was a large storage area of a petrochemical company in Zhuhai. The area consisted of 3 tank group and located in the independent fire compartments. The V101 tank in the tank group 1 was opted as the specific calculation object and the results were extended to the whole tank farm. The specific circumstances are shown in Tables 1-3 and Fig. 1. 
Table 1 Materials of tank group 1

\begin{tabular}{|c|c|c|c|c|c|}
\hline Number & Volume $\mathrm{m}^{3}$ & Material & $\begin{array}{c}\text { Storage } \\
\text { temperature } / \mathrm{C}\end{array}$ & $\begin{array}{c}\text { Storage } \\
\text { quality kg }\end{array}$ & $\begin{array}{c}\text { Design } \\
\text { pressurePa }\end{array}$ \\
\hline V101 & 5000 & Toluene & Homoeothermy & 3400 & 103625 \\
\hline v102 & 5000 & Toluene & Homoeothermy & 3480 & 103625 \\
\hline v103 & 5000 & Toluene & Homoeothermy & 3100 & 103625 \\
\hline V104 & 5000 & Toluene & Homoeothermy & 3400 & 103625 \\
\hline V105 & 5000 & Toluene & Homoeothermy & 3450 & 101000 \\
\hline V106 & 5000 & Toluene & Homocothermy & 3450 & 101000 \\
\hline
\end{tabular}

Table 2 Materials of tank group 2

\begin{tabular}{|c|c|c|c|c|c|}
\hline Number & $\begin{array}{l}\text { Volume } / \mathrm{m}^{3} \\
\end{array}$ & Material & $\begin{array}{c}\text { Storage } \\
\text { temperature } \\
\end{array}$ & $\begin{array}{l}\text { Storage } \\
\text { quality } k g\end{array}$ & $\begin{array}{c}\text { Design } \\
\text { pressurePa }\end{array}$ \\
\hline V201 & 5000 & Ethyl acetate & Homoeothermy & 3600 & 103625 \\
\hline $\mathrm{V} 202$ & 5000 & Ethyl acetate & Homoeothermy & 3500 & 103625 \\
\hline V203 & 5000 & Ethyl acetate & Homoeothermy & 3400 & 103625 \\
\hline V204 & 5000 & Ethyl acetate & Homoeothermy & 3450 & 103625 \\
\hline V205 & 5000 & Acetone & Homoeothermy & 3500 & 103625 \\
\hline V206 & 5000 & Acetone & Homoeothermy & 3400 & 103625 \\
\hline
\end{tabular}

Table 3 Materials of tank group 3

\begin{tabular}{|c|c|c|c|c|c|}
\hline Number & Volume $\mathrm{m}^{3}$ & Material & $\begin{array}{c}\text { Storage } \\
\text { temperature } / \mathrm{C}\end{array}$ & $\begin{array}{c}\text { Storage } \\
\text { quality } k \text { gg }\end{array}$ & $\begin{array}{c}\text { Design } \\
\text { pressure } / \mathrm{Pa}\end{array}$ \\
\hline V301 & 5000 & Xylene & Homoeothermy & 1752 & 103625 \\
\hline V 302 & 5000 & Xylene & Homocothermy & 2000 & 103625 \\
\hline V303 & 5000 & Methanol & Homoeothermy & 3000 & 101000 \\
\hline V304 & 5000 & Methanol & Homoeothermy & 2500 & 101000 \\
\hline V305 & 5000 & Acetone & Homoeotherny & 1500 & 103625 \\
\hline V306 & 5000 & Acetone & Homoeothermy & 2400 & 103625 \\
\hline
\end{tabular}

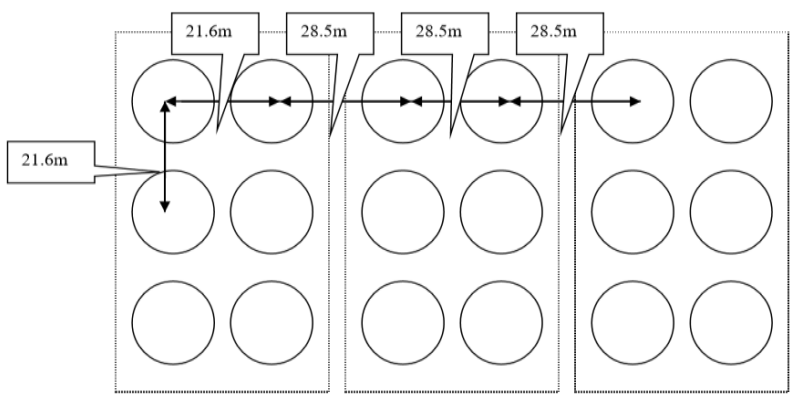

Fig. 1 Plan of tank farm

\subsection{Conformation of Fire and Explosion Index}

Firstly, V101 was calculated. Checking the storage area of toluene critical mass was $20 \mathrm{t}$, calculating:

\section{$\mathrm{W}_{1}=3400 / 20000=0.17$}

Toluene was flammable substances and the chemical activity was not obvious, so $\mathrm{W}_{2}$ taken 1.2 .

The toluene in the unit was stored at normal temperature without chemical reaction, so the state index of toluene was as follows:

$\mathrm{W}_{3}=103625 / 101325=1.0227$

Fire and explosion risk index for computing devices: $\mathrm{W}=0.17 \times 1.2 \times 1.0227=0.2086$

\subsection{Analysis of Domino effect Index}

As long as the primary accident of the tank near the distance was analyzed, because the tank was surrounded by other tanks. The typical domino accident of toluene tank was pool fire. The main factor affecting the domino effect intensity of toluene tank fire was toluene reserve, therefore, selecting of V102 with large reserves in the calculation of accident risk.

The boiling point of toluene was $110.6^{\circ} \mathrm{C}$, which higher than the ambient temperature. The heat of combustion of toluene was $359.81 \mathrm{~kJ} / \mathrm{kg}$, the cnstant pressure ratio heat capacity was $1.1266 \mathrm{~kJ} /(\mathrm{kg} \cdot \mathrm{K})$, the evaporation heat at boiling point was $3.09 \mathrm{~kJ} / \mathrm{kg}$, By calculation:

$\mathrm{m}_{\mathrm{f}}=0.0036193 \mathrm{~kg} /\left(\mathrm{m}^{2} \cdot \mathrm{s}\right)$

The liquid pool was the plane of the storage tank and the inner diameter of the tank was $23.7 \mathrm{~m}$, air density was
$1.293 \mathrm{~kg} / \mathrm{m} 3$, The flame length was calculated:

$$
\mathrm{L}=5.2367 \mathrm{~m}
$$

The total heat release rate was:

$\mathrm{Q}_{\mathrm{r}}=574.49 \mathrm{~kJ} / \mathrm{s}$

Surface radiant energy:

\section{$\mathrm{E}=0.040 \mathrm{~kJ} /\left(\mathrm{m}^{2} \cdot \mathrm{s}\right)$}

In the case of pool fire, the distance between the object and the storage tank was $21.6 \mathrm{~m}$, and the atmospheric transmittance was calculated:

$$
\tau=0.8217
$$

When calculating domino effect, the selected element spacing was based on the distance between research object and the main primary accident unit .

Thermal radiation flux:

$\mathrm{q}=0.03287 \mathrm{~kJ} /\left(\mathrm{m}^{2} \cdot \mathrm{s}\right)$

It was assumed that all the toluene in the tank was burned in the accident to calculate the maximum accident risk. Burning time was:

$\mathrm{t}=2129.45 \mathrm{~s}$

The calculated thermal dose was:

$\mathrm{I}=69.995 \mathrm{~kJ} / \mathrm{m}^{2}$

The domino failure threshold ${ }^{[5]}$ of the tank in the pool fire scenario was $15 \mathrm{~kJ} / \mathrm{m}^{2}$ (more than 10 minutes).According to the results, the combustion time was more than 10 minutes, so the domino threshold was adopted.

$$
\mathrm{D}=4.67
$$

\subsection{Evaluation of Terrorist Attacks Risk}

The plane figure in the literature did not give a specific boundary and chemical distance, this hypothesis: The left side of tank group 1 was the boundary of Chemical Zone. The distance was half of tank spacing plus fire channel width. The storage tank spacing was $21.6 \mathrm{~m}$, and the fire channel width was $4.5 \mathrm{~m}$, so the boundary distance between tank and chemical zone was $15.3 \mathrm{~m}$. The assumed distance was based on the minimum distance between the fire dike and the storage tank, the storage tank and the industrial zone boundary, and the fire safety requirements. Therefore, the impact of the shock wave generated by explosives decreased with increasing distance. The calculated explosion overpressure was the largest under the minimum distance and the danger index calculated by this overpressure was the most conservative as well.

Explosives for $33 \mathrm{~kg}$ TNT equivalent, calculated accordingly:

$\mathrm{P}_{\mathrm{S}}=32.1 \mathrm{kPa}$

Unit failure threshold was $22 \mathrm{kPa}$,Calculated the risk index for terrorist attacks:

\section{$\mathrm{T}=1.46$}

According to the tank area plan, it could be seen that the nearest storage tanks were V101, V103, V105, and the other tanks were far away from the chemical zone boundaries. The distance between V102, V104, V106 storage tank and chemical area boundary was $15.3 \mathrm{~m}$ adding the tank diameter was $38 \mathrm{~m}$, Calculated overpressure:

\section{$\mathrm{P}_{\mathrm{S}}=14.8 \mathrm{kPa}$}

It can be found out that the explosion overpressure was less than the failure threshold of the equipment, so the 
terrorist attack risk index of 1 . In the tank group 2 and tank group 3, the distance between the tank and the chemical zone boundary was greater, and the overpressure caused by explosion was smaller, therefore, the risk of terrorist attacks and other various index storage tanks were taken 1 .

\subsection{Synthetic Screening Hazard Index of Units Based on Risk of Domino Effect and Terrorist Attack}

According to the above steps to calculate the various indexes of each tank, the results of each tank were summarized:

$$
\begin{aligned}
& Z_{101}=0.2086 \times 4.77 \times 1.46=1.4528 \\
& Z_{102}=0.2135 \times 4.67 \times 1=0.9970 \\
& Z_{103}=0.1902 \times 4.74 \times 1.46=1.3163 \\
& Z_{104}=0.2086 \times 4.77 \times 1=0.9950 \\
& Z_{105}=0.2117 \times 4.74 \times 1.46=1.4650 \\
& Z_{106}=0.2117 \times 4.74 \times 1=1.0035
\end{aligned}
$$

The results shown that the size of the hazard index: $Z_{105}>Z_{101}>Z_{103}>Z_{106}>Z_{104}>Z_{102}$.

A more dangerous chemical unit can be screened out in the light of the size of the hazard index. The most dangerous one was V105 and the least dangerous was V102. Used this model to screen out the dangerous tanks was tank group 1 that it could be regarded as the basis for the next step of targeted safety protection improvement measures. It was indispensable to give priority to V105 security input in the case of limited resources.

\subsection{Sorting for Hazard Index of Chemical Units}

The results of the storage tanks were summarized below:

Tanks in tank group 2:

$\mathrm{Z}_{201}=0.1980 \times 1.21 \times 1=0.2396$

$\mathrm{Z}_{202}=0.1925 \times 1.24 \times 1=0.2387$

$\mathrm{Z}_{203}=0.1870 \times 1.24 \times 1=0.2319$

$Z_{204}=0.1898 \times 1.21 \times 1=0.2297$

$Z_{205}=0.1925 \times 1.17 \times 1=0.2252$

$\mathrm{Z}_{206}=0.1870 \times 1.19 \times 1=0.2225$

Tanks in tank group 3:

$\mathrm{Z}_{301}=0.0193 \times 6.30 \times 1=0.1216$

$\mathrm{Z}_{302}=0.0220 \times 5.52 \times 1=0.1214$

$\mathrm{Z}_{03}=0.0330 \times 6.30 \times 1=0.2079$

$Z_{304}=0.0275 \times 5.52 \times 1=0.1518$

$\mathrm{Z}_{305}=0.0825 \times 1.42 \times 1=0.1171$

$\mathrm{Z}_{306}=0.1320 \times 0.89 \times 1=0.1175$

Sorting tanks in tank group

$2: Z_{20} 1>Z_{202}>Z_{203}>Z_{204}>Z_{205}>Z_{206}$;

Sorting tanks in

$3: Z_{303}>Z_{304}>Z_{301}>Z_{302}>Z_{306}>Z_{305}$;

Sorting all tanks in the tank area: $Z_{105}>Z_{101}>Z_{103}>Z_{106}>Z_{104}>Z_{102}>Z_{201}>Z_{202}>Z_{203}>Z_{204}$ $>Z_{20} 5>Z_{206}>Z_{303}>Z_{304}>Z_{301}>Z_{302}>Z_{306}>Z_{305}$.

According to the above analysis, it can be seen that V105 was the most dangerous storage tank in the tank farm, the second was V101; V201 was the most dangerous in the tank group 2, V303 was the most dangerous in the tank group 3; Tanks in tank group 1 were more dangerous than tanks in other tank groups and tanks in tank group 3 were safer. The source of danger in the tank farm could be screened out according to the results obtained. Therefore, it can provide the basis for the next safety improvement and protection measures. Priority to the more dangerous tanks or tank group in limited safety investment was given to get the maximum safety benefits and to gain the best safety and economy.

The domino risk was evaluated by analyzing the impact of the unit in the case of an accident the surrounding unit occurred. Therefore, the calculated domino effect index taken the unit caused the greatest impact as the research object. It can be made out that the fire and explosion risk index of the unit was different due to the different storage materials and reserves of the unit through calculation. There were differences in the analysis object of the unit owing to the different effects caused by the accident around the unit. Some units may have a greater impact of accident, hence the peripheral units may reference the same risk source when analyzing the domino effect hazard index. Therefore, a plurality of devices may have the same hazard index of domino effect.

\section{Conclusions}

A model of hazard screening based on domino effect and terrorist attack was established in this paper:

(1) Drawn lessons from the fire and explosion hazard index method of Dow Chemical, the main accident scenarios of the unit was set up based on the quantity, nature and state of hazardous substances in the chemical unit. Afterwards the risk of unit under domino effect was evaluated according to domino effect intensity and failure threshold. Three hypotheses were made in the light of the actual situation, and the danger of terrorist attack was determined by the distance between the unit and the boundary of the chemical industry as the core. Combined with two indices, the comprehensive risk index of the unit was made sure.

(2) In the relevant data, the study of domino effect mainly focused on the interaction between units and the role of other units. This paper chose another angle to study the affected units which was analyzed by the impact of other unit accidents to research the danger under the domino effect.

(3) Three hypotheses were made in the analysis of the risk of terrorist attacks, thus setting specific scenarios for terrorist attacks. The impact of terrorist attacks in this scenario was calculated, and the risk of terrorist attack was determined simultaneously.

(4) The risk index of the unit can be computed after defining the domino effect and the risk of terrorist attacks, according to which the dangerous chemical unit was screened. Finally, it can be seen that the rapid screening efficiency of the model provided a scientific basis for the supervision of dangerous sources and the establishment of safety protection measures when this model is used for a specific case analysis.

\section{Acknowledgements}

The financial support of the Natural Science Foundation 
of Shanghai (16ZR1408500), the Technology Development Foundation of China Sinopec Qingdao Safety Engineering Institute (313038), the project for Development of Systems of Quantitative Risk Assessment of Domino Effect in the Chemical Industry (B100-81414), the Natural Science Foundation of Jiangsu Province (BK2012824) and Innovation Practice Training Program for college students (Accident risk analysis of typical ground and underground installations in petrochemical industry , S19098) are gratefully acknowledged.

\section{References}

1. LANDUCCI Gabriele, RENIERS Genserik, COZZANI Valerio. (2015) Vulnerability of industrial facilities to attacks with improvised explosive devices aimed at triggering domino scenarios $[\mathrm{J}]$. Reliability Engineering and System Safety, 143, 53-62.

2. ZHANG Zheng. (2005) A Research on Risk Analysis Theory and Risk Assessment Method of Terrorist Attacks in Industrial Facilities [D]. Nankai University, Tianjin.

3. LI Shuqian. (2008) A Study on the Overall Risk Assessment of Chemical Industrial Park Based on Domino Effect [D]. Nanchang University ,Nanchang.

4. CHEN Guohua, ZHANG Xinmei. (2007) Risk assessment and regulatory countermeasures of major risk sources[J]. Journal of Safety and Environment, 7(3), 132-136(in chinese).

5. COZZANI Valerio, GUBINELLI Gianfilippo, SALZANO Ernesto. (2006) Escalation thresholds in the assessment of domino accidental events[J]. Journal of Hazardous Materials, 129(1-3), 1-21. 